\title{
The Relationship Between Learning Organization and Job Satisfaction: Case Study of Palestinian Municipalities
}

\author{
Mohammed Nawaf Jallad \\ Palestine Technical University-Kadoorie, Tulkarm, Palestine
}

\begin{abstract}
This study aims to test the relationship between learning organization and job satisfaction from the perspective of the staff of Tulkarem Municipality - Palestine. The study uses seven independent variables: continuous learning, inquiry and dialog, team learning, embedded system, empowerment, system connection, strategic leadership, and their effect on job satisfaction. the study uses a survey in regards to test the hypotheses and answer the study questions, as this kind of data collations are more convenient from others methods. The findings from multiple regression tests show there is a statistically significant impact of strategic leadership and continuous learning on job satisfaction. The recommendations are that managers could build programs and systems to encourage learning at all levels.
\end{abstract}

Keywords: Continuous learning, Team learning, Embedded system, System connection, Strategic leadership

DOI: $10.7176 / \mathrm{EJBM} / 13-20-08$

Publication date:October $31^{\text {st }} 2021$

\section{Introduction}

Given the enormous scale of the advancement of information technology, globalization, and the many challenges facing organizations, it was the responsibility of companies to look for new strategies and effective management methods to tackle these challenges (Daryani et al, 2014). The most significant of these modern concepts is the idea of learning organizations, which in turn promotes new concepts and aspects such as collaborative thinking, shared vision, strategic leadership (Watkins and Marsick's,1997) which in turn reflects on the organization's intellectual capital, which in turn is the most important elements of growth, which plays an important role in the organization's success (Razali et al, 2013; Lim, 2010). The local municipalities, through the services they provide to citizens, which are increasing in quantity and quality because of technological progress and increasing population, need to periodically evaluate performance for development, modernization, and error correction. The organization's success is inevitably related to the quality of the human element, which in effect is influenced by many emotional and organizational variables that impact its performance positively or negatively.

The importance of this study emerges from the importance of the concept of the learning organization as being a determinant of the success of organizations as an important source of the value of the organization as well as one of the most important variables related to the study of behavior, which is among the most important factors that help organizations achieve their goals, accomplish their tasks, enhance creativity, trust between management and the workers, so this study seeks to clarify and understand the nature of the relationship between the learning organization in the institution under study and the job satisfaction of its employees.

Therefore, the aim of this study is to find the relationship between learning organization and job satisfaction in Palestinian municipalities, this study will focus on Tulkarm Municipality -as a case study- in regarding to answer the study question and testify the hypothesis, thus find the relationship between learning organization and job satisfaction.

\subsection{Research questions:}

The study attempted to answer the following questions:

1. Is there a relationship between learning organization and job satisfaction?

2. Is there a relationship between Continuous learning and job satisfaction?

3. Is there a relationship between Inquiry and dialog and job satisfaction?

4. Is there a relationship between Team learning and job satisfaction?

5. Is there a relationship between Empowerment and job satisfaction?

6. Is there a relationship between embedded systems and job satisfaction?

7. Is there a relationship between System connection and job satisfaction?

8. Is there a relationship between leadership and job satisfaction?

\subsection{Research hypothesis:}

The study hypotheses were developed based on the literature review such as (Razali et al, 2013), (Lim, 2010), (Dirani, 2009), (Dekoulou, \& Trivellas. 2015).

H1. Continuous learning has a positive effect on job satisfaction.

H2. Inquiry and dialog have a positive effect on job satisfaction. 
H3. Team learning has a positive effect on job satisfaction.

H4. An Embedded system has a positive effect on job satisfaction.

H5. Empowerment has a positive effect on job satisfaction.

H6. System connection has a positive effect on job satisfaction.

H7. Strategic leadership has a positive effect on job satisfaction.

\section{Literature Review \\ 2.1 Learning organization}

The learning organization has recently emerged remarkably, with many studies, literature, and research on the subject as a tool to improve profitability, competitiveness, and improve organizational work (Dekoulou P., \& Trivellas, P. 2015). Learning organization is collective learning organic ' systems ' rather than impersonal administrative devices or market-driven institutions based on self-interest and competition (Erdem, et al, 2014). The definition introduced by Peter Senge in (1990) clarified that learning organization is the organizations where people are continuously increasing their ability to create the outcomes they want, thinking about new and expanded patterns feeds, collective ambition is freed and people are constantly learning how to learn together (Senge,1990). Based on Watkins and Marsick's (1997) framework, was identified the seven dimensions of the learning organization are: (i) continuous learning opportunities: learning is designed to enable people to learn at work; opportunities for ongoing education and growth are provided. (ii) Inquiry \&dialog: people are open enough to express their views and can hear and examine others ' views; culture is changed to encourage interrogation, feedback, and experimentation. (iii) Team learning \& collaboration: groups are used in designing work to reach different forms of thinking. (vi) Empowerment: the people are involved in creating, owning, and carrying out a common vision; accountability is spread close to decision making so that people can learn what to do. (v) Embedded system: achieving the exchange of learning with work is done by establishing and integrating low and high technology systems and then providing access to them, maintaining them (Watkins \& Marsick 2003).(iv) system connection: the learning organization is based on a close relationship between the organization and various social, economic, religious, political, and technical powers (Lim, 2010). (vii) leadership: Watkins and Marsick (2003) stated that "Leaders model, champion, and support learning; leadership uses learning strategically for business results." In other words, we can emphasize that building a learning organization needs organized and supportive leadership within the organization (Lim, 2010).

Many studies have partially or completely addressed the 7th dimensions of the learning organization or organizational learning, such as the study for (Dirani, 2009) that was conducted on Lebanese banks employees, the results showed that the most dimension of the learning organization is practiced is strategic leadership, and the least is a team learning, as well as the study of (Razali et al, 2013), that was conducted on a group of academics from public universities in Malaysia and whose results showed that most dimensions are practice Also the strategic leadership dimension but the least dimension was establishing systems to capture and share learning. Based on Senge's (1990) study was identified the five dimensions of a learning organization, which are: (i) Personal Mastery: Clarify and deepen the personal vision continuously and see the reality objectively (ii) Mental models: This dimension relates to how our internal photos are brought out accurately and objectively (iii) Shared vision: It is the ability to carry a common image of the future that the institution wants to reach and that promotes creativity and innovation. (vi) Team Learning: It is the process of developing the team's capabilities to achieve the results that the institution wants to achieve, and dialogue is an essential point in the team's learning. (v) System thinking: It is a process that reflects the vision of the entire system and an understanding of the interrelations within it. These five dimensions, used by (Erdem, et al, 2014) study were conducted on a group of primary school teachers in the Turkish province of Van, and the results showed that the dimension agreed upon by most teachers is the team's learning and the least agreed dimensions is personal mastery. (Al Shoqran,2013), the purpose of this study was to determine the availability of the Senge dimensions of the learning organization from the point of view of employees at the Irbid University College in Jordan, the study results showed that the availability of these dimensions was in average, and the personal mastery came the first, the shared vision came in second place, a mental model came in the last so the study recommended Providing financial support to enhance the practices of expelling the learning organization and developing traditional administrative methods into modern methods.

\subsection{Job satisfaction}

One of the most important outcomes of work centered on individual organizational well-being is job satisfaction, which is a key factor in influencing success, competition, and organizational performance (Dekoulou, \& Trivellas,2015). Briefly can know job satisfaction is the degree of employee love for his job, and more deeply is the employee's emotional responses to his job based on the difference between desired and actual results (Razali et al, 2013). Job satisfaction is very important for individuals, groups, and therefore the entire organization because individuals who are satisfied with their work in institutions generally have mental and physical health and a better standard of living that enables them to do their jobs better than others. After all, they have motivations to work 
that support them to work harder (Erdem, et al, 2014). Research results have typically shown that job satisfaction influences the ability of individuals to support their colleagues and business partners, their actions in their willingness to cooperate and engage in various forms to sustain organized frameworks regulating the work environment (Dirani, 2009).

The main objective of (Ellickson, 2002) study was to test the relative impact of environmental and demographic variables on the variance in job satisfaction for municipal government employees serving the Midwest region in the United States, the findings of the study showed clearly that demographic variables relatively poor in job satisfaction predictors, on the other hand, environmental factors such as promotional opportunities, satisfaction with pay and benefits, satisfaction with performance assessment, resources \& equipment, training, workload, supervisory relationships, and most importantly, departmental corps spirit were significantly and positively related to overall job satisfaction. (Castillo \& Cano, 2004) these study aimed to describe the amount of variance in overall level of job satisfaction for faculty members at the College of Food, Agricultural, and Environmental Sciences at The Ohio State University, the study found there is job satisfaction among faculty members in general, noting that the rate of female satisfaction is lower than that of males. However, the results indicate that the most motivating factors for faculty members are "the job itself" and "working conditions" are the least motivating factors. Finally, the study for (Masum, et al, 2015) that aimed to know the factors that contribute to increasing or limiting job satisfaction. The study was conducted on a sample of academics working in private universities in Bangladesh. According to the results of the study, the most important factors affecting job satisfaction for academics were the compensation package, job security, and working conditions. The researchers recommended that university administration should focus on several issues that would enhance job satisfaction for academics such as training, financial benefits, infrastructure, fair evaluation, flexible work rules, and creating a supportive organizational culture.

\subsection{Learning organization and job satisfaction}

When researching famous scientific sites such as Scopus, Google scholar you find many studies dealing with the subject of the learning organization and many studies also deal with the concept of job satisfaction but find few studies linking the concept of a learning organization with the concept of job satisfaction.

(Khalib et al, 2015) this study aimed at developing a conceptual framework for organizational learning capabilities or organizational learning based on its review of several previous kinds of literature. Four independent variables were identified (organizational culture, leadership, dialogue, and participative decision-making); while the dependent variable is job satisfaction, the study concluded that practitioners should consider working conditions such as organizational learning capability and its dimensions when seeking to improve employee satisfaction. Studies for (Erdem, et al, 2014 ; Razali et al, 2013) aimed to study a relation between learning organization and job satisfaction, both studies were conducted on a sample of educational institutions, the first study sample was the primary school teachers in the province of Van in Turkey, used Senge's dimensions, but the second study was a sample of lecturers from several public universities in Malaysia used Watkins and Marsick's dimensions, both of which used the questionnaire tool to collect data, the results of both studies showed a positive correlation between learning organization and job satisfaction, to shed more light on the results of the two studies, the study of (Erdem, et al, 2014) clearly showed that the shared vision was first variable and the team learning second variable as significant independent variables predicted teachers' job satisfaction, other independent variables as dimensions of learning organizations; 'personal mastery', 'mental models' and, 'system thinking' were not significant predictors of teachers' job satisfaction, on the other hand the results for study (Razali et al, 2013) showed clearly that the strategic leadership was the most significant predictor of overall job satisfaction, followed by the continuous learning environment connection, encourage collaboration, and team learning, but the promote dialogue \& inquiry, and embedded system was not significantly correlated to overall job satisfaction.

Other quantitative studies focused on the relationship between the job satisfaction variable and the learning organization variable but with the addition of another variable to their study as the organizational commitment variable, (Lim, 2010) study in one Korean private organization and (Dirani, 2009), in the Lebanese banking sector, both studies adopted the seven dimensions of the learning organization((continuous learning opportunities, inquiry \&dialog, team learning, empowerment, embedded system, system connection, leadership ). The results of a study (Lim, 2010) showed the culture of learning organizations is related to job satisfaction moderately and positively; also organizational commitment was found to be moderately and positively related to the culture of the learning organization and job satisfaction, except continuing commitment, among the most important implications of this study is that managers could build programs and systems that encourage learning at all levels within the organization (individuals, groups, the organization as a whole); in addition to that, they could motivate, and encourage employees towards learning within the organization to improve job satisfaction and organizational commitment. On the other hand, (Dirani, 2009) study results indicated a strong relationship between the study's three variables, also the study recommended the necessity of enhancing the dimensions of the learning organization inside the bank, which has a positive role in the satisfaction and performance of employees; also the study 
emphasized the importance of the participation process, which is achieved by responding to the needs of employees and enabling them and working with them together towards learning.

Finally, the study of (Dekoulou, \& Trivellas, 2015) aimed to examine the relationship between learning organization, job satisfaction, and individual performance also findings have shown that learning-oriented activity is a primary indicator of both job satisfaction and individual performance for workers, while job satisfaction has proven to be a mediator of the relationship between learning organization and job performance, the study concluded that the Greek advertising companies should encourage employees at all levels for creativity, innovation and allow them to express their opinions and ideas. Also, the study recommended that these companies should also remain in strong contact with their work environment by achieving the welfare of employees taking into consideration Customer opinions and market trends in organizational and administrative processes, and enhance understanding, learning, and thinking with a global vision.

\section{Research methodology}

\subsection{Data collection and Variables Definition:}

The study chose a random sample from 150 responses were selected for Tulkarm Municipality employees as a focusing organization to find the relationship between learning organization and job satisfaction. The first part of the questionnaire consisted of demographic data, about gender, age, education, and experience. The second part of the questionnaire consisted of 47 items, associated with the study variables. Each item was measured on a fivepoint Likert scale beginning from Strongly Agree (1) to Strongly Disagree (5). we were used SPSS to analyze all data in this study. Cronbach Alpha was used to confirm the reliability of Likert scale items. Multiple regressions were used to assess the study hypotheses. Therefore, for confirmation of the study hypotheses, table (1) presents the operational definitions of study variables in the following table:

Table (1): Variables Definition

\begin{tabular}{|l|l|}
\hline Variable & Operational definition \\
\hline $\begin{array}{l}\text { Continuous Learning Opportunities } \\
\text { (CLO) }\end{array}$ & $\begin{array}{l}\text { Learning is designed to enable people to learn at work; opportunities } \\
\text { for ongoing education and growth are provided (Watkins \& Marsick } \\
\text { 2003). }\end{array}$ \\
\hline $\begin{array}{l}\text { Inquiry \&Dialog } \\
\text { (IAD) }\end{array}$ & $\begin{array}{l}\text { People are open enough to express their views and can hear and } \\
\text { examine others 'views; culture is changed to encourage interrogation, } \\
\text { feedback, and experimentation (Watkins \& Marsick 2003). }\end{array}$ \\
\hline $\begin{array}{l}\text { Team Learning \& Collaboration } \\
\text { (TL) }\end{array}$ & $\begin{array}{l}\text { Groups are used in designing work to reach different forms of } \\
\text { thinking (Watkins \& Marsick 2003). }\end{array}$ \\
\hline $\begin{array}{l}\text { Embedded system } \\
\text { (Em) }\end{array}$ & $\begin{array}{l}\text { achieving the exchange of learning with work is done by establishing } \\
\text { and integrating low and high technology systems and then providing } \\
\text { access to them, maintaining them(Watkins \& Marsick 2003). }\end{array}$ \\
\hline $\begin{array}{l}\text { System Connection } \\
\text { (SC) }\end{array}$ & $\begin{array}{l}\text { The people are involved in creating, owning, and carrying out a } \\
\text { common vision; accountability is spread close to decision making so } \\
\text { that people can learn what to do (Watkins \& Marsick 2003). }\end{array}$ \\
\hline $\begin{array}{l}\text { Strategic leadership } \\
\text { (SL) }\end{array}$ & $\begin{array}{l}\text { The learning organization is based on a close relationship between the } \\
\text { organization and various social, economic, religious, political, and } \\
\text { technical powers (Lim, 2010). }\end{array}$ \\
\hline $\begin{array}{l}\text { Job Satisfaction } \\
\text { (JS) }\end{array}$ & $\begin{array}{l}\text { Watkins and Marsick (2003) stated that "Leaders model, champion, } \\
\text { and support learning; leadership uses learning strategically for } \\
\text { business results." }\end{array}$ \\
\hline $\begin{array}{l}\text { The degree of employee love for his job, and more deeply is the } \\
\text { employee's emotional responses to his job based on the difference } \\
\text { between desired and actual results (Razali et al, 2013). }\end{array}$ \\
\hline
\end{tabular}

\subsection{Model Development:}

The study model was developed based on previous studies such as (Razali et al, 2013), (Lim, 2010), (Dirani, 2009), (Dekoulou, \& Trivellas, 2015). Developing the study model presents in graph (1): 


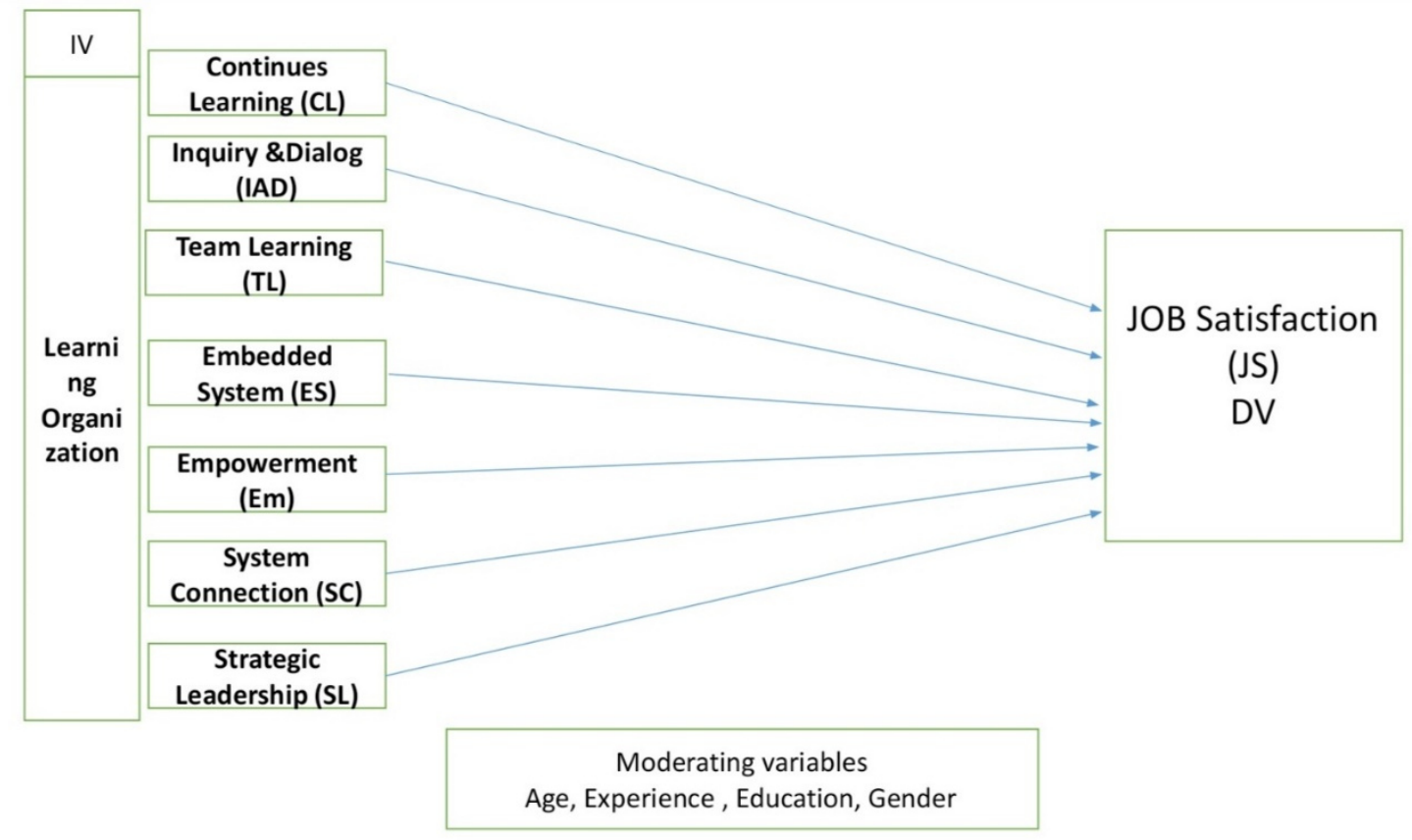

Therefore, the study model can be written as:

Graph (1): the study model

$\mathrm{JS}=\beta 0+\beta 1 \mathrm{CL}+\beta 2 \mathrm{IAD}+\beta 3 \mathrm{TL}+\beta 4 \mathrm{ES}+\beta 5 \mathrm{Em}+\beta 6 \mathrm{SC}+\beta 7 \mathrm{SL}$

Where,

JS: job satisfaction, CL: continuous learning, IAD: inquiry and dialog, TL: team learning, ES: embedded system, EM: empowerment, SC: system Connection SL: strategic leadership, $\beta$ : the coefficient

\subsection{Questionnaire design:}

We developed a questionnaire to examine the relationship between organizational learning and job satisfaction from the perspective of the staff of Tulkarem Municipality - Palestine. A questionnaire developed by previous researchers with acceptable reliability and validity indicators was reviewed. In our research was translated the questionnaire from English to Arabic, and the questionnaire was distributed to the staff of Tulkarem Municipality carefully.

\section{Findings}

\subsection{The Characteristics Description:}

The study sample consisted of (133) employees of Tulkarm municipality, table (2) shows the distribution of the sample depending on the personal variables.

Table (2): The Gender

\begin{tabular}{|ll|l|l|l|l|}
\hline & Frequency & Percent & Valid Percent & Cumulative Percent \\
\hline Valid & male & 91 & 68.4 & 68.4 & 68.4 \\
& 42 & 31.6 & 31.6 & 100.0 \\
& female & 100.0 & 100.0 & \\
\hline & Total & 133 & &
\end{tabular}

From table (2), we can note that for the gender variable, the highest percentage reached (68.4\%) for (Male), but the lowest percentage reached (31.6\%) for (Female). Further, table (3) the age variable description: Table (3): The Age

\begin{tabular}{|ll|l|l|l|l|}
\hline & Frequency & Percent & Valid Percent & Cumulative Percent \\
\hline Valid & $20-30$ & 30 & 22.6 & 22.6 & 22.6 \\
& $30-40$ & 55 & 41.4 & 41.4 & 63.9 \\
& $40-50$ & 36 & 27.1 & 27.1 & 91.0 \\
& 50 and above & 12 & 9.0 & 9.0 & 100.0 \\
& Total & 133 & 100.0 & 100.0 & \\
\hline
\end{tabular}

From table (3), we can note that for Age variable, the highest percentage reached (41.4\%) for (From 30-40 years), but the lowest percentage reached $(9.0 \%)$ for (50 and above). Table (4) presents the responders' education 
level analysis;

Table (4): The Education

\begin{tabular}{|ll|l|l|l|l|}
\hline & & & & Cumulative \\
& & Frequency & Percent & Valid Percent & \begin{tabular}{l} 
Percent \\
\hline Valid
\end{tabular} high school \\
diploma & 21 & 15.8 & 15.8 & 15.8 \\
& 36 & 27.1 & 27.1 & 42.9 \\
bachelor degree & 65 & 48.9 & 48.9 & 91.7 \\
postgraduate & 11 & 8.3 & 8.3 & 100.0 \\
Total & 133 & 100.0 & 100.0 & \\
\hline
\end{tabular}

From table (4), we can note that in the education variable, the highest percentage reached (48.9\%) for (bachelor degree), but the lowest percentage reached (8.3\%) for (postgraduate). Further, table (5), presents the responders' analysis for the experience variable:

Table (5): The Experience

\begin{tabular}{|ll|l|l|l|l|}
\hline & & & & Cumulative \\
& & Frequency & Percent & Valid Percent & Percent \\
\hline Valid & $1-5 y$ & 21 & 15.8 & 15.8 & 15.8 \\
& $5-10$ & 25 & 18.8 & 18.8 & 34.6 \\
$10-15$ & 38 & 28.6 & 28.6 & 63.2 \\
$15-20$ & 49 & 36.8 & 36.8 & 100.0 \\
Total & 133 & 100.0 & 100.0 & \\
\hline
\end{tabular}

From table (4), we can note that the experience variable, the highest percentage reached (36.8\%) for (1520years), but the lowest percentage reached (15.8) for (1-5years).

\subsection{Testing the Reliability and Normality:}

This section presents the reliability and normality distribution analysis for the questionnaire, as an appendix (A) shows that the Cronbach's Alpha is 0.953 , which indicates the reliability results, is accepted. Furthermore, appendix (B) presents the normality distributions analysis by using the Kolmogorov - Smirnov Z, which applied to dependent and independent variables to revealed normality, curve normality are display. (p) Value for each variable more than sig. level (0.05), this indicates to normality distribution for variables data, the following table shows that.

\section{Scale Correction:}

Formed questionnaire final form of (47) paragraph, where the study used Likert scale to include fivesome to gauge the views of the study sample members, was given strongly agree (5), Agree (4), Neutral (3), Disagree (2), Strongly Disagree (1). Further, used signal $(\sqrt{ })$ in front of the answer, which reflect the degree of consent, it has also been relying on the following classification of the rule on the averages as follows:

- Less than the 2.33 Low.

- From 2.34 to 3.66 Medium.

- More than the 3.67 High.

Descriptive statistics:

This section presents the descriptive statistics for the study variables; table (6) presents the descriptive statistics: Table (6): Statistics

\begin{tabular}{|ll|l|l|l|l|l|l|l|}
\hline & & CL & IAD & TL & ES & Em & SC & SL \\
\hline $\mathrm{N}$ & Valid & 133 & 133 & 133 & 133 & 133 & 133 & 133 \\
& Missing & 0 & 0 & 0 & 0 & 0 & 0 & 0 \\
Mean & & 2.5263 & 2.7459 & 2.8835 & 3.1368 & 3.0959 & 3.0737 & 2.9654 \\
\hline
\end{tabular}

The above table shows that: The highest means reached (3.1368) for Embedded System by medium agreement degree, but the lowest for Continues Learning, by medium agreement degree (means 2.5263). The total means for all learning organization dimensions was (2.91) to medium agreement level. Furthermore, appendix (C) presents descriptive statistics for job satisfaction total means for the job satisfaction variable was (2.92) to medium agreement level.

\subsection{The Hypotheses Testing}

To test these Hypotheses, and to detect the relationship between organizational learning and job satisfaction from the perspective of the staff of Tulkarem Municipality - Palestine, the (Liner Regressions) analysis was used, the following tables clear that: 
Model Summary b

\begin{tabular}{|c|c|c|c|c|c|c|c|c|c|c|}
\hline \multirow[t]{2}{*}{ Model } & \multirow[b]{2}{*}{$\mathrm{R}$} & \multirow[b]{2}{*}{ R2 } & \multirow[b]{2}{*}{ Adj. R2 } & \multirow[b]{2}{*}{ Std. Error } & \multicolumn{5}{|c|}{ Change Statistics } & \multirow[b]{2}{*}{$\begin{array}{l}\text { F Durbin- } \\
\text { Watson }\end{array}$} \\
\hline & & & & & $\begin{array}{l}\mathrm{R} \text { Square } \\
\text { Change }\end{array}$ & \begin{tabular}{|l} 
F \\
Change
\end{tabular} & dff & df2 & $\begin{array}{l}\text { Sig. } \\
\text { Change }\end{array}$ & \\
\hline JS* & $.683 a$ & .466 & .436 & .77885 & .466 & 15.595 & 7 & 125 & .000 & 1.952 \\
\hline
\end{tabular}

a. Predictors: (Constant), SL, IAD, CL, ES, SC, Em, TL

*b. Dependent Variable: job satisfaction (JS)

The regression equation was significant with the independent variables accounting for about $64.6 \%$ of the total variance $(\mathrm{R} 2=.466, \mathrm{p}=.000)$. It meant $64 \%$ in variation in the job satisfaction has been explained by the dimension of a learning organization.

ANOVAb

\begin{tabular}{|ll|l|l|l|l|l|}
\hline Model & & Sum of Squares & df & Mean Square & F & Sig. \\
\hline 1 & Regression & 66.222 & 7 & 9.460 & 15.595 & $.000 \mathrm{a}$ \\
& Residual & 75.826 & 125 & .607 & & \\
Total & 142.048 & 132 & & & \\
\hline
\end{tabular}

a. Predictors: (Constant), SL, IAD, CL, ES, SC, Em, TL

b. Dependent Variable: JS

The p-value of the ANOVA test is less than 0.05 so we can confirm that the least one independent variables is statistically significant explaining variation in job satisfaction.

Coefficientsa

\begin{tabular}{|c|c|c|c|c|c|c|c|c|}
\hline \multirow{2}{*}{\multicolumn{2}{|c|}{ Model }} & \multicolumn{2}{|c|}{ Unstandardized Coefficient } & \multirow{2}{*}{\begin{tabular}{|l} 
Standardized \\
Coefficients \\
Beta \\
\end{tabular}} & \multirow[b]{2}{*}{$\mathrm{t}$} & \multirow[b]{2}{*}{ Sig. } & \multicolumn{2}{|c|}{ Collinearity Statistics } \\
\hline & & $\mathrm{B}$ & Std. Error & & & & Tolerance & VIF \\
\hline \multirow[t]{8}{*}{1} & (Constant) & .346 & .281 & & 1.234 & .220 & & \\
\hline & $\mathrm{CL}$ & .282 & .140 & .199 & 2.017 & .046 & .441 & 2.269 \\
\hline & IAD & .055 & .105 & .049 & .522 & .602 & .476 & 2.102 \\
\hline & TL & -.119 & .173 & -.101 & -.687 & .493 & .198 & 5.044 \\
\hline & $\mathrm{ES}$ & .142 & .126 & .126 & 1.125 & .263 & .341 & 2.933 \\
\hline & Em & -.095 & .124 & -.097 & -.769 & .443 & .267 & 3.743 \\
\hline & $\mathrm{SC}$ & .106 & .126 & .096 & .835 & .405 & .324 & 3.089 \\
\hline & $\mathrm{SL}$ & .533 & .141 & .495 & 3.786 & .000 & .250 & 3.997 \\
\hline
\end{tabular}

a. Dependent Variable: JS

Of all seven variables, strategic leadership with value $(\mathrm{p}=.000)$ was the most significant predictor of overall job satisfaction, followed by continuous learning $(\mathrm{p}=.046)$. Therefore, the hypothesis number 1 and 7 were accepted. On the other hand inquiry \& dialogue $(\mathrm{p}=.522)$, team learning $(\mathrm{p}=0.493)$, empowerment $(\mathrm{p}=.443)$, system connection $(p=.405)$, establishing system $(p=.263)$, were not significantly correlated to overall job satisfaction. Therefore, the hypothesis number 2, 3, 4,5and 6 were rejected. At this end, for leadership dimension was the most predictor of overall job satisfaction, inquiry, dialogue, and establishing the system, were not significantly correlated to overall job satisfaction are matching with the findings for studies (Razali et al, 2013).

\section{Conclusions and policy implications}

The most important goals of corporate management are to increase job satisfaction for employees and to improve the efficiency of employees, which will inevitably reflect on their performance, so our study suggests several methods for that:

The managers could build programs and systems that encourage learning at all levels; in addition to that, they could motivate, and encourage employees towards learning within the organization to improve job satisfaction (Lim, 2010). Further, they could focus on several issues that would enhance job satisfaction for employees such as training, financial benefits, infrastructure, fair evaluation, flexible work rules, and creating a supportive organizational culture (Masum, et al, 2015). Moreover, they could consider working conditions such as organizational learning capability and its dimensions when seeking to improve employee satisfaction (Khalib et al, 2015). From here, the future research will be on the same topic, but the study sample will be on all municipalities in the northern West Bank in Palestine and compare the results with each other.

\section{References}

Al-Shoran, A. (2013).The degree of availability of learning organization controls for Senge in Irbid University College from the point of view of employees: obstacles and development proposals, European Scientific 
Journal, 9(5), 1857-7881

Castillo, J. X., \& Cano, J. (2004). Factors explaining job satisfaction among faculty. Journal of Agricultural Education 45(2), 19-27.

Dekoulou, P., \& Trivellas, P. (2015). Measuring the Impact of Learning Organization on Job Satisfaction and Individual Performance in the Greek Advertising Sector. Procedia - Social and Behavioral Sciences, 175, $367-375$.

Dirani, K. M. (2009). Measuring the learning organization culture, organizational commitment and job satisfaction in the Lebanese banking sector. Human Resource Development International, 12(2), 189-208.

Daryani, S.M.,Ardabili, F.S. and Amini, M. (2014) 'The study models of learning organization building', Int. J. Learning and Intellectual Capital, Vol. 11, No. 4, pp.320-333.

Ellickson, M. C., \& Logsdon, K. (2002). Determinants of Job Satisfaction of Municipal Government Employees. Public Personnel Management, 31(3), 343-358.

Erdem, M., İlğan, A. \& Uçar, H.İ. (2014). Relationship between Learning Organization and Job Satisfaction of Primary School Teachers. International Online Journal of Educational Sciences, 6(1), 8-20.

Khalib, L. H., Kassim, N. A., Ghazali, F. I., Jaafar, N., \& Idris, A. (2015). Organizational Learning Capabilities (OLC) toward Job Satisfaction: A Conceptual Framework. Academic Research International, 6 (2), 169-180.

Lim, T. (2010). Relationships among organizational commitment, job satisfaction, and learning organization culture in one Korean private organization. Asia Pacific Education Review, 11(3), 311-320.

Masum, A. K. M., Azad, M. A. K., \& Beh, L.-S. (2015). Determinants of Academics' Job Satisfaction: Empirical Evidence from Private Universities in Bangladesh. PLOS ONE, 10(2), e0117834. doi:10.1371/journal.pone.0117834.

Razil, M.Z.M, \& Amira, N. A., and Shobri, M. D.N, (2013) "Learning Organization Practices and Job Satisfaction among Academicians at Public University," International Journal of Social Science and Humanity vol. 3, no. 6, pp. 518-522.

Senge, P. (1990). The Fifth Discipline: The Art and Practice of the Learning Organization, New York: Doubleday. Watkins, K. E., \& Marsick, V. J. (1997). Dimensions of the learning organization questionnaire (survey). Warwick, RI: Partners for the Learning Organization.

Watkins, K. E., \& Marsick, V. J. (2003). Demonstrating the value of an organization's learning culture: The dimensions of the learning organization questionnaire. Advances in Developing Human Resources, 5(2), 132151.

\section{Appendices:}

Appendix (A)

Reliability Statistics

\begin{tabular}{|l|l|}
\hline Cronbach's Alpha & N of Items \\
\hline .953 & 47 \\
\hline
\end{tabular}

\section{Appendix (B)}

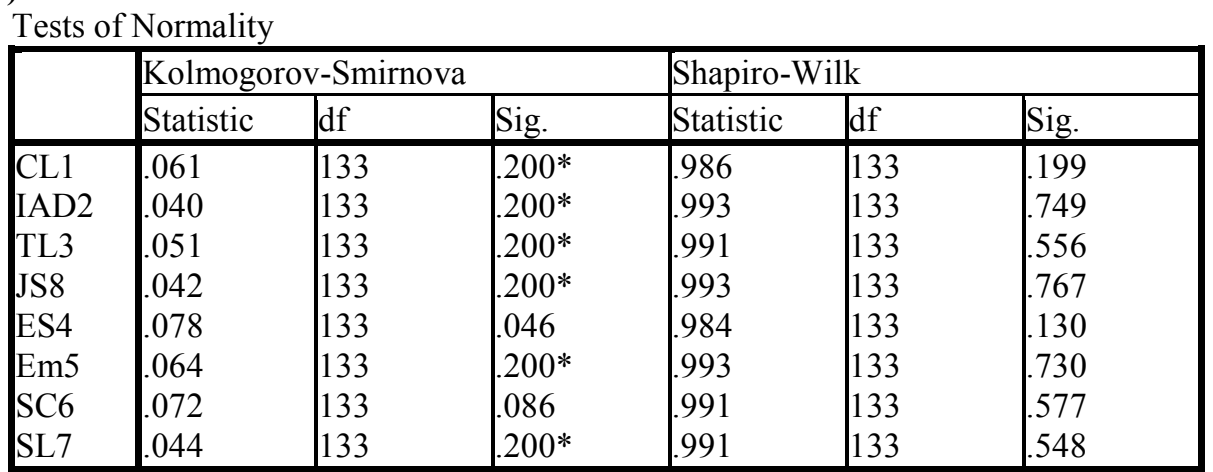

a. Lilliefors Significance Correction

*. This is a lower bound of the true significance.

\section{Appendix (C)}

Job satisfaction Statistics
\begin{tabular}{|ll|l|}
\hline $\mathrm{N}$ & Valid & 133 \\
& Missing & 0 \\
Mean & & 2.9248 \\
\hline
\end{tabular}

